\title{
Teacher Competence And The Academic Achievement Of Sixth Grade Students In Uganda
}

Robert Wamala, Makerere University, Uganda

Gerald Seruwagi, University of Incarnate Word, USA

\begin{abstract}
The study investigates the influence of teacher competence on the academic achievement of sixth grade students in Uganda. The investigation is based on data sourced from the 2009 Southern African Consortium for Monitoring Education Quality (SACMEQ) survey comprising 5,148 records of sixth grade students enrolled in primary schools in Uganda. The percentage scores of students and teachers in reading and numeracy tests were adopted as measures of academic achievement and competence, respectively. The analysis was carried out using a multiple linear regression clustered by six geographical regions in Uganda - eastern, western, southern, northern, southwestern, and northeastern. In addition to teacher competency, students' academic achievement in the various disciplines was modeled by the student characteristics of age, sex, rural-urban residence, class repetition status (any class), and length of pre-primary education. The results showed students' high academic achievement in reading and numeracy was significantly associated with high teacher competency in the same disciplines. However, this generalization may not hold for all students in all countries because of variations in learner characteristics and the learning environment. Nevertheless, the findings suggest the need to strengthen teacher competence as a measure to enhance students' academic achievement in formal education.
\end{abstract}

Keywords: Student Academic Achievement and Teacher Competency; Academic Achievement of Sixth Grade Students; Uganda

\section{INTRODUCTION}

n response to the 1990 World Conference on Education for All (EFA) and the United Nations Millennium Development goals (MDGs), the government of Uganda introduced Universal Primary Education (UPE). As a result, the enrollment rates increased from 16\% in 1996 to $73 \%$ in 1997 and have increased at a rate of five percent every year since then (MoES 2008). Over 87\% of the total enrollment of primary schools in Uganda is in government-aided schools, according to results of the Education Statistical Abstract (MoES, 2009).

Though the rate of student enrollment has risen, especially at the lower primary levels, the education sector is still faced with a number of challenges related to teaching and learning — insufficient and poorly trained, under motivated teachers, overcrowded classrooms, and a shortage of teaching/learning materials (UWEZO, 2012). In light of the aforementioned challenges, the quality of learner outcomes, especially in government-aided primary schools, remains a cause for serious concern in Uganda. Given the learning environment, it is not surprising that a number of learners in many developing countries, including Uganda, fail to master basic literacy and numeracy even after six years of schooling (Nannyonjo, 2007). The education sector continues to register low learning outcomes despite enormous investments in the primary sub-sector to improve educational quality in terms of the curriculum and learning environment as well as the teaching and learning processes (UWEZO, 2012). For example, the 2009 Uganda Education Statistical Abstract reveals a high rate of class repetition (12.2\%) in primary schools despite the 
automatic promotion policy (MoES, 2009). A class analysis of repetition reveals the highest rates, which are in first grade (p. 1) and sixth grade (p. 6), can be attributed to underage students and pre-candidates deemed unfit for endof-cycle exams, respectively. The repetition estimates for first and sixth grade are $13.5 \%$ and $12.9 \%$, respectively (MoES, 2009). Repetition of the first grade in Uganda has been attributed to the enrollment of underage students. The underage issue seems to imply that these students have either not gone through or only partially attended preprimary education, even though literature consensually regards the pre-primary stage to be important in the development of young children before they enter formal schooling (e.g., Kaul, 2002; Ramachandran, Jandhyala, \& Saihjee, 2003; Govinda \& Bandyopadhyay, 2008).

On the other hand, more controversy exists with regard to which teacher characteristics and practices influence student academic achievement. Hanushek's (2004) study presents four aspects for debate with regard to the subject matter: (i) Is it the length of teacher training that matters? (ii) Or, is it the teacher's experience? (iii) Does what a teacher knows about the subject matter? (iv) Or, is it more important to understand what a teacher does in his or her classroom? Certainly, the answers to these questions are critical at a time when the international community has committed itself to ensuring that all children have access to free and quality primary education by the 2015 MDG target. A majority (63.9\%) of primary school teachers in Uganda is Grade III - which is the minimum level of professional teacher qualification in primary education (MoES, 2009). With Grade III as the stipulated minimum requirement, the vast majority of teachers in Uganda (90.6\%) are reported to be qualified for acceptable standards in the country. However, the quality of education in UPE schools particularly continues to decline (MoES, 2008). To remedy this, a number of interventions geared towards improving the academic achievement of learners in primary education have been suggested. While the National Assessment of Progress in Uganda study (UNEB, 2009) has recommended increasing education inputs (e.g., teachers, classrooms, textbooks, and staff houses), Goloba, Wokadala, and Bategeka (2010) suggest employing child-centered approaches as opposed to teacher-centered methods of teaching. Nanyongo's (2007) study of education inputs in Uganda suggests parent involvement, school environment, and teacher characteristics play a vital role in a student's learning achievement. Nonetheless, despite the increased supply of education inputs in primary schools, the quality of education in UPE schools has continued to decline (MoES 2008). Further, Goloba et al. (2010) suggest an urgent need to focus more on teacher supervision in order to compel teachers to attend to their duties. However, primary school teachers' competence with regard to the disciplines they handle is assumed. Recent studies in Uganda have focused on either students' academic achievement or teachers' competence in the disciplines they teach (SACMEQ, 2009; UNEB, 2011). However, these studies do not relate teachers' competence to the academic achievement of the students they teach. In an attempt to rectify this, a study of the achievement of S.2 (Form Two) students and teachers in Uganda reveals that students taught by teachers with a Degree in Education (post-secondary) have higher achievement than those whose teachers had Grade V (secondary) (UNEB, 2011). Teachers with a higher education qualification are suggested to have a stronger grounding in their disciplines (UNEB, 2012). Nevertheless, no statistical assessment has been made to ascertain whether the difference in the performance of students taught by teachers with various levels of academic qualifications is significant. The aspect of contention is not necessarily the lack of academically qualified teachers in Uganda's primary schools, but rather their competence skills for the disciplines they teach.

Nevertheless, the fact that primary education is, in many ways, the core of the schooling system, the need to ensure that effective teaching and learning takes place should be a priority for all concerned parties. This study therefore investigates the influence of teacher competence on the academic achievement of sixth grade students in Uganda. Apart from teacher competence, the analysis controls for differentials in students' background characteristics, including age, sex, rural-urban residence, length of pre-primary education, and repetition status (any class).

\section{DATA AND METHODS}

The investigations were based on data sourced from the 2009 Southern African Consortium for Monitoring Education Quality (SACMEQ) survey conducted in Uganda, Tanzania, and Malawi; students were the unit of analysis. A sample of 5,148 sixth grade students enrolled in 163 randomly selected primary schools in Uganda was obtained based on the International Association for the Evaluation of Educational (IAEE) standards - the estimates of student population parameters having a sampling accuracy equivalent to a simple random sample of 400 students. The selection guarantees a $95 \%$ confidence limit for sample means of plus or minus one-tenth of a student standard 
deviation unit. However, small-size schools (i.e., those with fewer than 15 or 20 sixth grade students) were excluded from the study because of their low representation of the total student population. In addition, these schools were mostly located in isolated areas and were thus associated with high costs of data collection. With regard to sampling design, an explicit and implicit stratification of students was performed by region and school size as measured by the number of sixth grade students. Probability proportional to size (PPS) was adopted to obtain the number of schools in each stratum - region and school size. In each of the selected schools, a simple random sample of sixth grade students was gathered using the attendance registers of students who regularly attended classes.

Data collection was carried out using a pre-designed questionnaire, test data for individual students, and a "tracking form" for the purpose of data cleaning. The test construction was undertaken carefully to ensure that the structure of student tests in reading and numeracy was congruent with the content (domains) and behaviors (skills) derived from detailed analyses of the curricula, syllabi, exams, and textbooks used in the country. The tests included "overlapping" test items selected from five earlier studies: the Zimbabwe Indicators of the Quality of Education Study (Ross, 1995), SACMEQ I and SACMEQ II Projects, IEA's Third International Mathematics and Science Study (Mullis et al, 2001), and IEA's International Study of Reading Literacy (Elley, 1992). The scoring on reading, health science, and numeracy tests was based on the Rasch technique - international mean of 500 with a standard deviation of 100. However, percentage scores (100\%) in the various disciplines were adopted as the measure of students' academic achievement in the analysis. On the other hand, the percentage test scores of teachers in similar schools and disciplines were adopted as the measure of teachers' competency. In the event that a teacher taught reading and numeracy, tests in both disciplines were given. Otherwise, the teachers took the test that matched the discipline they taught.

In the analysis, the influence of teacher competency on student academic achievement in the various disciplines was investigated using a multiple linear regression clustered by six geographical locations of schools adopted in the assessment - eastern, western, south, northern, southwestern, and northeastern. The analysis was modeled by a series of student characteristics including age, sex, length of pre-primary schooling, rural-urban residence, and class (any) repetition status.

\section{RESULTS}

The study participants were sixth grade students in selected schools of Uganda. They are characterized as follows. There was a similar proportion of males and females, and the median age was 16 years (range: 12-27). Slightly more than half (52.6\%) of the participants did not attend pre-primary school and $23.4 \%$ attended for about a year, while the rest spent more than a year in pre-primary school. With regard to the status of having repeated a grade, slightly more than four in every nine $(46.8 \%)$ had never repeated a grade, while the rest had repeated either once $(35.8 \%)$ or twice $(17.4 \%)$. The analysis in the subsequent section is clustered by the geographical location of schools, referred to as the region in this study. The highest proportion of participants were enrolled in the eastern region $(26.9 \%)$, followed by the central region $(24.3 \%)$, northern region $(21.1 \%)$, and western region $(12.8 \%)$. The rest of the students were from the northeastern $(6.1 \%)$ and southwestern $(8.8 \%)$ regions.

\section{Multivariate Assessment of Teacher Competency and Student Academic Achievement}

The academic achievement of sixth grade students was modeled by teacher competency and student background characteristics in a multiple linear regression clustered by region. Table 1 presents regression estimates in the various disciplines.

Table 1

Estimates of Student Academic Achievement on Teacher Competence in Reading and Numeracy Clustered by Region ${ }^{\text {a }}$

\begin{tabular}{|l|c|c|}
\hline Independent Variables & \multicolumn{2}{|c|}{ Discipline $^{\text {Numeracy }^{\mathbf{c}}}$} \\
\cline { 2 - 3 } Sex & Reading $^{\mathbf{b}}$ & \\
\hline Male $^{\dagger}$ & &. \\
\hline Female & $-0.72^{* *}$ & $-1.17^{* *}$ \\
\hline Age & &. \\
\hline Below $14^{\dagger}$ & $\cdot$ & $-1.75^{* *}$ \\
\hline $15-19$ & $-3.03^{* *}$ & \\
\hline
\end{tabular}

(C) 2013 The Clute Institute http://www.cluteinstitute.com/ 


\begin{tabular}{|c|c|c|}
\hline 20 and Above & $-5.77 * *$ & $-2.75^{* *}$ \\
\hline \multicolumn{3}{|l|}{ Residence } \\
\hline \multicolumn{3}{|l|}{ Rural $^{\dagger}$} \\
\hline Small Town & $2.65^{* * *}$ & $2.03 * *$ \\
\hline Large City & $6.01 * *$ & $4.24 * *$ \\
\hline \multicolumn{3}{|c|}{ Pre-primary Schooling Period [months] } \\
\hline \multicolumn{3}{|c|}{ Never $^{\dagger}$} \\
\hline $1-12$ & -0.18 & 0.37 \\
\hline $13-24$ & $0.79 *$ & $1.78^{* *}$ \\
\hline 25 and Above & $0.76^{*}$ & $0.77 *$ \\
\hline \multicolumn{3}{|l|}{ Grade Repetition Status } \\
\hline \multicolumn{3}{|c|}{ Never $^{\dagger}$} \\
\hline Once & $-1.26 * *$ & $-0.66^{* *}$ \\
\hline Twice & $-1.43 * *$ & $-1.11 * *$ \\
\hline Teacher Competence & $0.09 * *$ & $0.03 * *$ \\
\hline cons & $43.62 * *$ & $46.66^{* *}$ \\
\hline
\end{tabular}

Note. Figures present coefficients; associations are established at the 5\% and 1\% level; where * $p<0.05$, ** $p<0.01 ;$ Groups $=6$.

${ }^{\dagger}$ Reference categories adopted.

${ }^{a}$ Regions investigated were Central, East, West, North, Northeast, and Southwest.

${ }^{\mathrm{b}} \mathrm{n}=4,170$, Wald Chi-square $=637.48, \mathrm{p}<0.001, \mathrm{ICC}=0.078$

${ }^{c} \mathrm{n}=4,033$, Wald Chi-square $=294.52, \mathrm{p}<0.001, \mathrm{ICC}=0.070$

\section{Regression Diagnostics}

Table 2 presents the Likelihood Ratio (LR) test estimates of modeling student academic achievement in the various disciplines using an ordinary MLR rather than a multilevel approach clustered by region. A summary of the findings is made subsequently.

A low probability value $(\mathrm{p}<0.05)$ for the LR Chi-square test in Table 2 affirms the existence of regional differentials in student academic achievement in reading and numeracy because the ICC is not equal to zero. In other words, an ordinary multiple regression should not be used to model the data - a multilevel model is needed. Further, the results suggest that the random intercept model fit the data better than the random coefficient model.

In light of the fact that the normality assumption of level-1 residuals is not required for consistent estimation of model parameters, standard errors, and asymptotic normality of the estimates (Sophia \& Anders, 2012), no distributional assumption diagnostic tests were performed on the residuals.

Table 2

Likelihood Ratio Test Estimates of Regression Clustered by Region vs. an Ordinary Multiple Linear Regression

\begin{tabular}{|c|c|c|c|}
\hline Random-Effects Parameters & Estimate & Std. Error & 95\% CI [Estimate] \\
\hline \multicolumn{4}{|l|}{ Reading } \\
\hline \multicolumn{4}{|l|}{ Region: Identity } \\
\hline sd(_cons $)^{b}$ & 1.95 & 0.57 & $1.09-3.49$ \\
\hline sd(Residual) & 6.68 & 0.07 & $6.53-6.82$ \\
\hline \multicolumn{4}{|l|}{$\chi^{2}=217.8$, p-value $<0.001^{\mathrm{a}}$} \\
\hline \multicolumn{4}{|l|}{ Numeracy } \\
\hline \multicolumn{4}{|l|}{ Region: Identity } \\
\hline sd(_cons) & 1.91 & 0.57 & $1.06-3.41$ \\
\hline sd(Residual) & 6.95 & 0.07 & $6.80-7.10$ \\
\hline
\end{tabular}

${ }^{\text {a} P r o c e e d i n g s ~ o f ~ L R ~ T e s t ~ — ~ w h e t h e r ~ e s t i m a t e d ~ v a r i a n c e ~ c o m p o n e n t ~ i s ~ d i f f e r e n t ~ f r o m ~ z e r o, ~ t h a t ~ i s, ~ n u l l ~ h y p o t h e s i s ~ o f ~ z e r o ~}$ variation due to regional clustering.

${ }^{\mathrm{b}}$ Standard deviation at region level 


\section{SUMMARY OF THE FINDINGS}

According to results of the multivariate assessment, using a multiple linear regression clustered by region, significant association of a student's performance was noted for all the background variables and teacher competency as shown by the test scores in the two disciplines $(\mathrm{p}<0.05)$. These results can be summarized as follows.

- Young sixth grade students (14 years and below) scored higher than their older counterparts (15 years and above) in all disciplines.

- $\quad$ Males scored higher than females in all disciplines.

- Students in small towns and large cities scored higher than those in rural areas in all disciplines.

- $\quad$ Students who had repeated a grade (once or twice) scored lower than those who had never repeated a class in all disciplines.

- $\quad$ Students who had spent two years or more in pre-primary education scored higher than their peers who did not attend pre-primary school in all disciplines.

- A higher score of students in reading and numeracy was associated with higher teacher competence represented by high test scores in similar disciplines.

Overall, variance at the regional level accounted for about $8 \%(\mathrm{ICC}=0.078)$ and $7 \%(\mathrm{ICC}=0.070)$ of the total variance in student academic achievement in reading and numeracy, respectively.

\section{DISCUSSION}

The results reveal the academic achievement of sixth grade students in reading and numeracy was significantly associated with teacher competency in similar disciplines $(\mathrm{p}<0.05)$. In particular, students' high scores in both disciplines were associated with teachers' high scores in similar disciplines. In the recent 2011 National Assessment of Progress in Uganda, higher performance by third and sixth grade teachers was associated with higher academic qualification (UNEB, 2011). The study reveals that primary school teachers who had the Uganda Advanced Certificate of Education (UACE) as their highest academic qualification performed better than those with the Uganda Certificate of Education (UCE). The argument is that teachers who have attained UACE have a stronger grounding in the subject matter. To this end, the suggestion to revise the minimum qualification for entry into Primary Teachers Colleges (PTC) to UACE is highly supported.

With regard to teachers' highest teaching qualification, the 2011 National Assessment of Progress in Uganda reveals better performance by Grade V holders than by Grade III holders in oral reading (UNEB, 2011). The argument is that the Grade V course allows for greater development of reading skills. The situation was not any different with regard to student achievement in secondary education. The study reveals that secondary education students taught by teachers with a degree in education performed better than their peers taught by teachers with a Grade V (secondary) or other qualification (UNEB, 2011). The findings suggest that the confidence a teacher derives from appropriate training is a key ingredient in quality teaching.

In addition, this study reveals significant differentials in the academic achievement of sixth grade students by their background characteristics of age, sex, rural-urban residence, length of pre-primary schooling, and repetition status $(\mathrm{p}<0.05)$. The findings suggest that higher teacher competency alone may not directly translate into better academic achievement by students. One must critically assess students' situation with regard to their background characteristics in order to obtain better academic achievement. Particularly, the lower performance of students in rural areas has been attributed to a higher rate of absenteeism of both students and teachers in these schools compared to those in urban areas (small and large towns). In light of the fact that a majority of schools in the rural areas are government-aided, the situation is made worse by the unfavorable learning environment characterized by higher enrollment rates that do not match the available resources, for example, teachers and learning materials.

With regard to age, learning difficulty or the involvement of older students in non-academic matters, especially in the rural areas, works counter to academic achievement (UNEB, 2012). Similarly, young students are associated with timely enrollment, which indicates a high degree of participation of the official school-age 
population (SACMEQ, 2011). In light of the stipulated age at commencement of a first grade student in Uganda, which is six years, the median age of students in this study (16, range: 12 to 27) was higher than the expected for a sixth grade student by about five years. This points to a high proportion of adult learners in sixth grade who are oftentimes associated with late starting and/or grade (any) repetition (e.g., SACMEQ, 2011; UNEB, 2012). It is not surprising that students who had repeated any class obtained lower grades in all disciplines than their peers who had never repeated a grade. The 2009 Uganda Education Statistical Abstract reveals a high rate of grade repetition by primary school students, despite the existence of an automatic promotion policy (MoES, 2009). The highest proportions of repeaters are noted in first grade (p. 1) and sixth grade (p. 2), estimated at $13.5 \%$ and $12.9 \%$, respectively. The argument that first grade repetitions are mainly due to underage students (MoES, 2009) suggests the need to underscore the attendance and/or length of pre-primary education. With regard to sixth grade repetitions, the argument that it is mainly due to pre-candidates deemed unfit to sit end-of-cycle exams, which is seventh grade, suggests that a considerable number of students have not mastered basic skills even after six years of school. Certainly, the poor academic achievement of a considerable number of students at this level (sixth grade) and higher levels of education is attributed, among other factors, to a poor start at the lower levels, including pre-primary education. In light of the fact that slightly more than a half (52.6\%) of the students in this study never attended preprimary school, it is unsurprising that a high proportion of grade repetition is reported among students in Uganda's primary schools, despite the automatic promotion policy.

The results showed that students who had at least two years of pre-primary education had higher scores in all disciplines compared to those who never or partially attended $(\mathrm{p}<0.01)$. The findings support literature that underscores the importance of pre-primary education in the development of young children before they enter formal schooling (e.g., Kaul, 2002; Ramachandran, Jandhyala, \& Saihjee, 2003; Govinda \& Bandyopadhyay, 2008). Ramachandran et al.'s (2003) study suggests that this stage helps children become more independent and promotes their overall development. Further, it is associated with a strong bearing on children's attendance and participation once they enter primary education. Pertaining to gender, pre-primary education enables girls in particular to attend school, thus making them free from family or work responsibilities such as sibling care and house chores (Bandyopadhyay \& Behera, 2010). In light of the fact that efforts towards attaining education for all in developing countries, including Uganda, seem to be centered upon universal primary and secondary education, the findings of this study suggest the need to emphasize pre-primary education as a measure of supporting students' academic achievement at higher schooling levels.

In sum, as much as teacher competence is associated with students' academic achievement, the generalization does not hold for all students in all countries. This is possibly due to differentials mainly in student characteristics and the learning environment, among other factors.

\section{AUTHOR INFORMATION}

Dr. Robert Wamala Ph.D, School of Statistics and Planning, Makerere University, Uganda. E-mail: rwamala@isae.mak.ac.ug (Corresponding author)

Dr. Gerald Seruwagi, Ph.D, University of the Incarnate Word, USA. E-mail: geraldtx@gmail.com

\section{REFERENCES}

1. Bandyopadhyay, M. \& Behera, J. (2010). Pre-primary Education in India. CREAT India Policy Brief 1. Retrieved from http://www.create-rpc.org/pdf documents/India Policy Brief_1.pdf

2. Goloba, W. \& Bategeka, L. (2010). Does teaching methods and availability of teaching resources influence pupils' performance: Evidence from four districts in Uganda. Economic Research Policy, Research Series No. 77. Retrieved from http://www.eprc.or.ug/pdf files/series77.pdf

3. Govinda, R. \& Bandyopadhyay, M. (2008) Access to elementary education in India: Country analytical review. New Delhi/Brighton: NUEPA and University of Sussex.

4. Hanushek, E. \& Rivkin, S. G. (2004). How to Improve the Supply of High Quality Teachers. Washington, DC: Brookings Institution. 
5. Kaul, V. (2002). Early Childhood Care and Education. In R. Govinda (Ed.), India Education Report. New Delhi: Oxford University Press.

6. MoES (2008). Uganda Education Statistical Abstract, Kampala, Ministry of Education and Sports (MoES).

7. MoES (2009). Uganda Education Statistical Abstract. Ministry of Education and Sports (MoES). Education Planning and Policy Analysis Department.

8. Nannyonjo, H. (2007). Education Inputs in Uganda. An Analysis of Factors Influencing Learning Achievement in Grade Six. Washington DC: The World Bank.

9. Ramchandran, V., Jandhyala, K., \& Saihjee, A. (2003). Through the life cycle of children: Factors that facilitate/impede successful primary school completion. Economic and Political Weekly, 38(47), 49945002.

10. UNEB (2011). The Achievement of Primary School Pupils in Uganda in Numeracy, Literacy and Oral Reading. National Assessment of Progress in Education, Uganda National Examinations Board (UNEB).

11. UNEB (2011). The Achievement of S 2 Students and Teachers in Uganda in English Language, Mathematics and Biology. National Assessment of Progress in Education, Uganda National Examinations Board (UNEB).

12. UWEZO (2010). Are our Children Learning? Annual Learning Assessment Report, Uganda. Retrieved from http://www.uwezo.net/wpcontent/uploads/2012/08/UG_2010_AnnualAssessmentReportSummary.pdf 


\section{NOTES}

